\title{
Inflammation-Induced Protein Unfolding in Airway Smooth Muscle Triggers a Homeostatic Response in Mitochondria
}

\author{
Debanjali Dasgupta, Philippe Delmotte and Gary C. Sieck * \\ Department of Physiology \& Biomedical Engineering, Mayo Clinic, Rochester, MN 55905, USA; \\ Dasgupta.debanjali@mayo.edu (D.D.); Delmotte.Philippe@Mayo.edu (P.D.) \\ * Correspondence: Sieck.Gary@mayo.edu; Tel.: +1-507-284-6850
}

Citation: Dasgupta, D.; Delmotte, P.; Sieck, G.C. Inflammation-Induced Protein Unfolding in Airway Smooth Muscle Triggers a Homeostatic Response in Mitochondria. Int. J. Mol. Sci. 2021, 22, 363. https://doi.org/ $10.3390 /$ ijms 22010363

Received: 20 November 2020 Accepted: 28 December 2020 Published: 31 December 2020

Publisher's Note: MDPI stays neutral with regard to jurisdictional clai$\mathrm{ms}$ in published maps and institutional affiliations.

Copyright: (C) 2020 by the authors. Licensee MDPI, Basel, Switzerland. This article is an open access article distributed under the terms and conditions of the Creative Commons Attribution (CC BY) license (https:// creativecommons.org/licenses/by/ $4.0 /)$

\begin{abstract}
The effects of airway inflammation on airway smooth muscle (ASM) are mediated by pro-inflammatory cytokines such as tumor necrosis factor alpha (TNF $\alpha)$. In this review article, we will provide a unifying hypothesis for a homeostatic response to airway inflammation that mitigates oxidative stress and thereby provides resilience to ASM. Previous studies have shown that acute exposure to TNF $\alpha$ increases ASM force generation in response to muscarinic stimulation (hyperreactivity) resulting in increased ATP consumption and increased tension cost. To meet this increased energetic demand, mitochondrial $\mathrm{O}_{2}$ consumption and oxidative phosphorylation increases but at the cost of increased reactive oxygen species (ROS) production (oxidative stress). TNF $\alpha$-induced oxidative stress results in the accumulation of unfolded proteins in the endoplasmic reticulum (ER) and mitochondria of ASM. In the ER, TNF $\alpha$ selectively phosphorylates inositol-requiring enzyme 1 alpha $(\mathrm{pIRE} 1 \alpha)$ triggering downstream splicing of the transcription factor X-box binding protein 1 (XBP1s); thus, activating the pIRE1 $\alpha / \mathrm{XBP} 1 \mathrm{~s}$ ER stress pathway. Protein unfolding in mitochondria also triggers an unfolded protein response ( $\left.{ }^{\mathrm{mt}} \mathrm{UPR}\right)$. In our conceptual framework, we hypothesize that activation of these pathways is homeostatically directed towards mitochondrial remodeling via an increase in peroxisome proliferator-activated receptor-gamma coactivator 1 alpha (PGC1 $\alpha$ ) expression, which in turn triggers: (1) mitochondrial fragmentation (increased dynamin-related protein-1 (Drp1) and reduced mitofusin-2 (Mfn2) expression) and mitophagy (activation of the Phosphatase and tensin homolog (PTEN)-induced putative kinase 1 (PINK1)/Parkin mitophagy pathway) to improve mitochondrial quality; (2) reduced Mfn2 also results in a disruption of mitochondrial tethering to the ER and reduced mitochondrial $\mathrm{Ca}^{2+}$ influx; and (3) mitochondrial biogenesis and increased mitochondrial volume density. The homeostatic remodeling of mitochondria results in more efficient $\mathrm{O}_{2}$ consumption and oxidative phosphorylation and reduced ROS formation by individual mitochondrion, while still meeting the increased ATP demand. Thus, the energetic load of hyper-reactivity is shared across the mitochondrial pool within ASM cells.
\end{abstract}

Keywords: reactive oxygen species (ROS); oxidative stress; Mfn2; Drp1; MCU; asthma

\section{Introduction}

Airway inflammation underlies a number of pathological conditions such as asthma, chronic obstructive pulmonary disease (COPD), chronic bronchitis, COVID-19 and various cough syndromes. With the COVID-19 pandemic, we are keenly aware of the detrimental impact of airway inflammation and acute respiratory distress syndrome (ARDS). Even before COVID-19, ARDS affected as many as 246,000 people in the USA each year (based on an incidence rate of $\sim 75$ per 100,000), with influenza and the common cold affecting many more. The effects of acute airway inflammation are mediated by pro-inflammatory cytokines (e.g., tumor necrosis factor alpha, $\mathrm{TNF} \alpha$ ) leading to increased contractile protein expression, increased force generation and increased ATP consumption in airway smooth muscle (ASM) [1,2]. In humans, the increase in ATP consumption in ASM is matched by increased mitochondrial $\mathrm{O}_{2}$ consumption at the expense of increased reactive oxygen 
species (ROS) formation (oxidative stress) [3]. The subsequent oxidative stress results in an accumulation of unfolded proteins in the endoplasmic reticulum (ER) and in mitochondria triggering unfolded protein responses in both organelles. In a recently published study, we demonstrated that $\mathrm{TNF} \alpha$ selectively activates the inositol-requiring enzyme 1 alpha (pIRE1 $\alpha$ ) mediated ER stress pathway in human ASM, which induces alternative splicing of mRNA for the transcription factor X-box binding protein 1 (XBP1s) [3]. In a follow-up study, we showed that $24 \mathrm{~h} \mathrm{TNF} \alpha$ exposure increases the expression of peroxisome proliferator-activated receptor-gamma coactivator 1 alpha (PGC1 $\alpha$ ) in human ASM cells, thereby promoting mitochondrial biogenesis and an increase in mitochondrial volume density [4]. The TNF $\alpha$ induced increase in PGC1 $\alpha$ and mitochondrial remodeling could be downstream to either ER stress or the mitochondrial unfolded protein response ( $\left.{ }^{\mathrm{mt}} \mathrm{UPR}\right)[5,6]$. In addition to playing a key role in mitochondrial biogenesis, PGC1 $\alpha$ also activates the Phosphatase and tensin homolog (PTEN)-induced putative kinase 1 (PINK1)/Parkin mitophagy pathway, which is involved in the ubiquitination of the mitochondrial fusion protein Mfn2 [7,8]. Accordingly, we found that acute exposure to TNF $\alpha$ also results in a decrease in mitofusin 2 (Mfn2) protein levels in human ASM cells while expression of dynamin-related protein-1 (Drp1) increases, resulting in mitochondrial fragmentation $[4,9,10]$. In addition to promoting mitochondrial fusion, Mfn2 also plays an essential role in tethering mitochondria to the ER, thereby establishing the proximity of mitochondria to ER $\mathrm{Ca}^{2+}$ release sites that represent microdomains of higher cytosolic $\mathrm{Ca}^{2+}$ concentrations ([Ca $\left.{ }^{2+}\right]_{\mathrm{cyt}}$ "hotspots") [9-12]. In another study, we reported that acute TNF $\alpha$ exposure disrupts the tethering of mitochondria to the $\mathrm{ER}$ and reduced mitochondrial $\mathrm{Ca}^{2+}$ influx through the mitochondrial $\mathrm{Ca}^{2+}$ uniporter (MCU) [13]. This is consistent with other studies showing that close proximity of mitochondria to the ER is necessary to open the $\mathrm{MCU}$ and thereby promote mitochondrial $\mathrm{Ca}^{2+}$ influx [9-12]. In this review article, we provide a conceptual framework for a homeostatic response triggered by activation of the pIRE1 $\alpha /$ XBP1s ER stress pathway, which serves to mitigate the impact of TNF $\alpha$-induced ER stress by promoting mitochondrial biogenesis, reducing mitochondrial $\mathrm{Ca}^{2+}$ influx and thereby limiting ROS formation (Figure 1). Components of this homeostatic response include a pIRE1 $\alpha /$ XBP1s-mediated increase in PGC1 $\alpha$ and an increase in PINK1/Parkin leading to: (a) a reduction in Mfn2 and restricted tethering of mitochondria to the ER, and (b) mitochondrial biogenesis leading to an increase in mitochondrial volume density, which reduces $\mathrm{O}_{2}$ consumption and ROS formation per mitochondrion, while still meet the increased ATP demand of force generation.

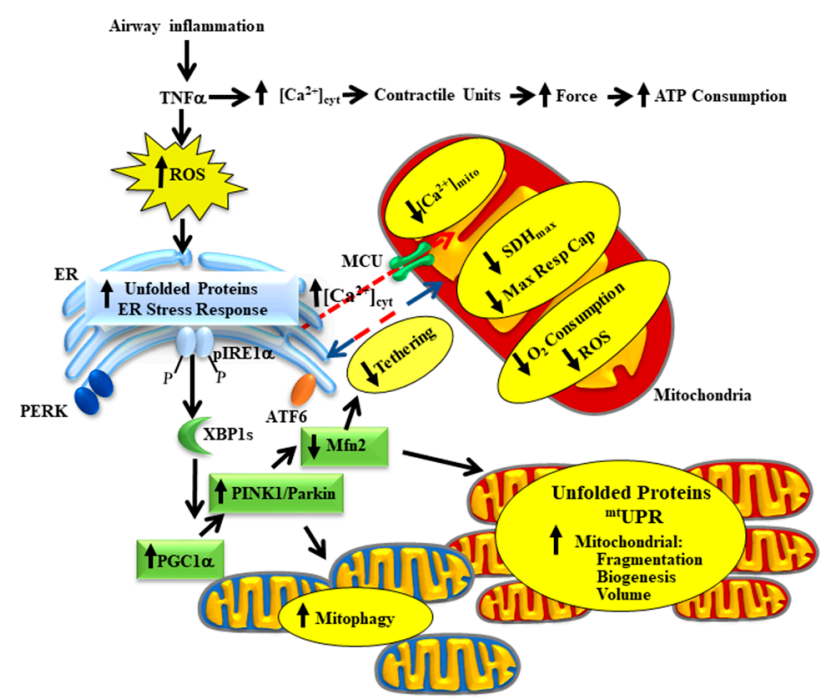

Figure 1. Our conceptual model hypothesizes that, following airway inflammation, TNF $\alpha$ induces an increase in airway smooth muscle (ASM) force generation and ATP consumption leading to increased mitochondrial $\mathrm{O}_{2}$ consumption and reactive oxygen species (ROS) production. TNF $\alpha$-induced ROS 
formation leads to protein unfolding and selective activation of the pIRE1 $\alpha /$ XBP1s endoplasmic reticulum (ER) stress pathway and a mitochondrial unfolded protein response ( $\left.{ }^{\mathrm{mt}} \mathrm{UPR}\right)$. Downstream XBP1s mediates an increase in PGC1 $\alpha$, PINK1/Parkin expression resulting in increased Drp1 and reduced Mfn2 expression, which leads to mitochondrial fragmentation and mitophagy. Reduced Mfn2 also disrupts mitochondrial tethering to the ER, thereby decreasing mitochondrial $\mathrm{Ca}^{2+}$ influx. Increased PGC1 $\alpha$ also promotes mitochondrial biogenesis and increased mitochondrial volume density. The homeostatic remodeling of mitochondria reduces $\mathrm{O}_{2}$ consumption and ROS formation by individual mitochondrion while still meeting the increased ATP demand. Thus, the energetic load of hyper-reactivity is shared across the mitochondrial pool within ASM cells.

\section{TNF $\alpha$ Increases ASM Force Generation, ATP Consumption and Tension Cost}

In ASM cells, agonist (e.g., acetylcholine-ACh)-induced increase in $\left[\mathrm{Ca}^{2+}\right]_{\text {cyt }}$ leads to a contractile response through a signaling cascade that involves $\mathrm{Ca}^{2+}$ binding to calmodulin $(\mathrm{CaM}), \mathrm{Ca}^{2+} / \mathrm{CaM}$ mediated activation of myosin light chain kinase (MLCK), phosphorylation of the regulatory myosin light chain $\left(\mathrm{rMLC}_{20}\right)$, myosin heavy chain $(\mathrm{MyHC})$ binding to actin (cross-bridge formation), attachment of actin filaments to the ASM membrane and force generation against an external load $[2,14,15]$. ASM force generation resulting from cross-bridge recruitment and cycling is driven by ATP hydrolysis $[1,2,16,17]$ (Figure 2). Recently, we showed that TNF $\alpha$ increases ASM force generation in response to muscarinic (ACh) stimulation [1,2]. The TNF $\alpha$-induced increase in ASM force is primarily due to an increase in contractile protein expression and is accompanied by a marked increase in ATP consumption and tension cost (ATP hydrolysis rate per unit of isometric force) [1,2]. Under normal physiological conditions, the tension cost of ASM is significantly lower than skeletal muscle; however, work efficiency is higher [16]. Thus, the energetics of ASM are perfectly suited to sustain a greater force at a lower energy cost.

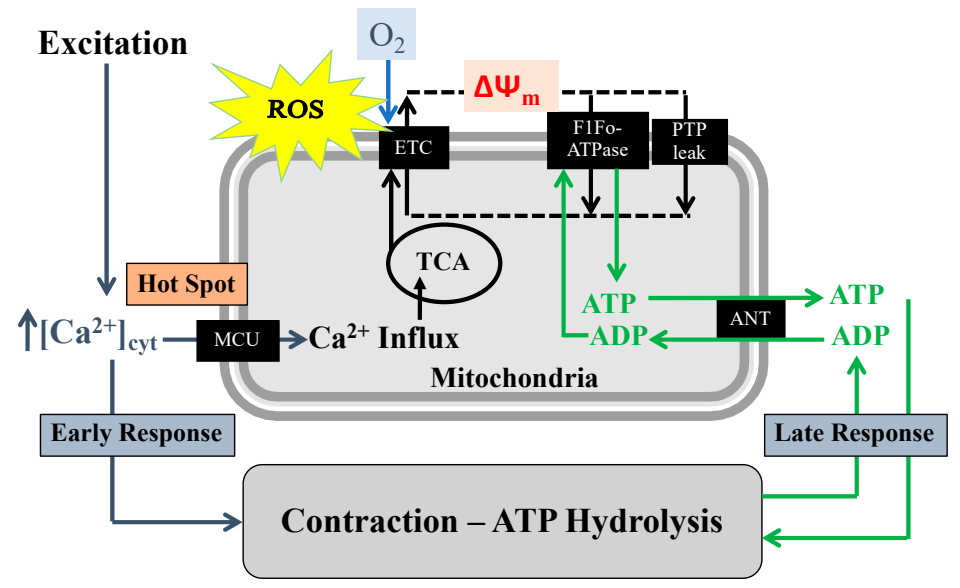

Figure 2. Our conceptual model demonstrates that in ASM cells, excitation, contraction, and energy production are coupled with two mechanisms. (1) On a shorter timescale, agonist-induced elevation of $\left[\mathrm{Ca}^{2+}\right]_{\text {cyt }}$ triggers activation of the mitochondrial $\mathrm{Ca}^{2+}$ uniporter (MCU) and $\mathrm{Ca}^{2+}$ influx, which increases tricarboxylic acid cycle (TCA) activity thereby providing $\mathrm{H}^{+}$to the electron transport chain (ETC). (2) On a longer timescale, agonist-induced force/contraction results in ATP consumption and an increase in ADP, which increases ADP influx into mitochondria via the adenosine nucleotide transporter (ANT), stimulating ATP synthase (F1Fo-ATPase) activity. With excessive mitochondrial $\mathrm{Ca}^{2+}$ influx, an overload in mitochondrial $\mathrm{Ca}^{2+}$ concentration $\left(\left[\mathrm{Ca}^{2+}\right]_{\text {mit }}\right)$ can trigger the opening of mitochondrial permeability transition pores (mPTP), which are large conductance channels present in the inner mitochondrial membrane that reduce the $\mathrm{H}^{+}$gradient and mitochondrial membrane potential $\left(\Delta \psi_{\mathrm{m}}\right)$. 


\section{TNF $\alpha$ Induced Oxidative Stress Triggers Protein Unfolding in the ER and Mitochondria}

In human ASM, we previously showed that TNF $\alpha$ exposure and increased ROS formation lead to an accumulation of unfolded proteins in the ER lumen, which trigger a homeostatic signaling cascade to restore normal function (i.e., ER stress response) [3]. As a positive control, we showed that all three ER stress signaling pathways (protein kinase RNA-like ER kinase (PERK), activating transcription factor 6 (ATF6) and IRE1 $\alpha$ ) were activated in response to tunicamycin. However, in response to TNF $\alpha$, only the pIRE1 $\alpha / X B P 1 s$ ER stress pathway was selectively activated in human ASM cells. Importantly, although the PERK and ATF6 ER stress pathways were activated by tunicamycin, they were not activated by TNF $\alpha$ [3]. The involvement of TNF $\alpha$-induced ROS formation in triggering the ER stress response in human ASM was confirmed by the fact that the ROS scavenger tempol blunted TNF $\alpha$-induced activation of the pIRE1 $\alpha /$ XBP1s ER stress pathway [3]. Moreover, we found that TNF $\alpha$ did not induce changes in expression of proteins downstream from activation of the PERK and ATF6 ER stress pathways (e.g., phosphorylation of eukaryotic initiation factor 2 alpha (p-eIF2 $\alpha$ ), activating transcription factor 4 (ATF4) and CCAAT-enhancer-binding protein homologous protein (CHOP)). Selective activation of ER stress pathways is not restricted to the pIRE1 $\alpha /$ XBP1s ER stress pathway but can involve PERK or ATF6 pathways as well [3,18]. It is possible that selective activation of ER stress pathways depends on the inducer and/or cell type. In this regard, it is possible that in ASM cells, the binding affinity of IRE1 $\alpha$ to the Grp78/BiP protein is lower than other ER stress sensors. Grp78/BiP dissociation triggers autophosphorylation of IRE1 $\alpha$ and activation of the pIRE1 $\alpha$ /XBP1s ER stress pathway. In asthmatic airway epithelial cells, it was reported that the expression of ER stress markers is elevated [19-21]; however, activation of specific ER stress pathways was not examined (e.g., phosphorylation of IRE1 $\alpha$ or PERK, or cleavage of ATF6). In a mouse model of asthma, chemical chaperones were shown to reduce the expression of ER stress markers in lung tissue and attenuate airway hyperresponsiveness [22-25]. However, as in the case of asthmatic airway epithelial cells, these studies using a mouse model did not examine the specific activation of different ER stress pathways.

Increased mitochondrial ROS formation can also lead to mitochondrial protein damage and unfolding, triggering the ${ }^{\mathrm{mt}} \mathrm{UPR}[5,26]$. As with the ER stress response, the ${ }^{\mathrm{mt}} \mathrm{UPR}$ is an adaptive response to buffer excess ROS, refold proteins or remove damaged proteins. Although the mechanisms of the ${ }^{\mathrm{mt}} \mathrm{UPR}$ have been extensively studied in Caenorhabditis elegans, the sensory mechanism of ${ }^{\mathrm{mt}} \mathrm{UPR}$ in vertebrate tissue is not clear. The canonical ${ }^{\mathrm{mt}}$ UPR pathway involves crosstalk between mitochondria and the nucleus via the recruitment of transcription factors such as CHOP, ATF4, and activating transcription factor 5 (ATF5). Acting together, these chaperones and transcription factors promote an integrated stress response (ISR) [27-29], resulting in the production of various antioxidants, chaperones and proteases to reduce stress and protein damage inside the mitochondrial matrix $[5,6]$. This ISR is coordinated with an ER stress response by phosphorylation of eIF $2 \alpha$ as a downstream effector of the PERK/eIF $2 \alpha$ ER stress pathway, which can be activated by increased ROS, amino acid depletion and ER dysfunction [26,30]. Considering the pro-apoptotic properties of CHOP and ATF5, it is hypothesized that uncontrollable ${ }^{\mathrm{mt}} \mathrm{UPR}$ can lead to cellular apoptosis $[5,28,31]$. However, as mentioned above, we found that TNF $\alpha$ exposure did not affect CHOP or ATF4 expression, nor does it trigger apoptosis. In addition to the canonical CHOP-ATF4-ATF5 mediated pathway, the ${ }^{\mathrm{mt}} \mathrm{UPR}$ also activates sirtuin-3-mediated transcriptional upregulation of superoxide dismutase 2 (SOD2) and catalase as an antioxidant response [5]. We cannot exclude a role of this ${ }^{\mathrm{mt}} \mathrm{UPR}$ pathway, particularly in mitigating mitochondrial ROS formation in ASM after TNF $\alpha$ exposure.

Another important consequence of mitochondrial ROS formation is transient opening of mitochondrial permeability transition pore (mPTP) and dissipation of the mitochondrial membrane potential $\left(\Delta \psi_{\mathrm{m}}\right)$ [32] (Figure 2). During conditions of excess ROS and $\mathrm{Ca}^{2+}$ overload, opening the mPTP helps to maintain $\mathrm{Ca}^{2+}$ levels in the mitochondrial 
matrix $[33,34]$. However, a dysregulation in $\mathrm{MPTP}$ opening results in the release of various matrix metabolites including NAD+ and leads to the $\Delta \psi_{\mathrm{m}}$ depolarization, inhibition of oxidative phosphorylation and ultimately mitochondrial damage [35-37].

\section{TNF $\alpha$-Induced Activation of pIRE1 $\alpha /$ XBP1s ER Stress Pathway Increases PGC1 $\alpha$ Expression, Mediating Mitochondrial Fragmentation, and an Increase in Mitochondrial Biogenesis}

In a recent study in human ASM, we found that TNF $\alpha$-induced activation of the pIRE1 $\alpha /$ XBP1s ER stress pathway is associated with an increase in PGC1 $\alpha$ expression (Figure 3A) [4], a protein known to play a significant role in regulating mitochondrial biogenesis and dynamic remodeling [38-40]. Importantly, PGC1 $\alpha$ is a known transcriptional target of XBP1s [41]. Additionally, PGC1 $\alpha$ can modulate the activity of another protein, PTEN-induced putative kinase 1 (PINK1) by cooperative binding and helps in its activation [42,43]. PINK1, together with Parkin, forms a well-known regulatory complex of the mitophagy pathway involved in mitochondrial remodeling. In other cell types, previous studies have reported that PINK1 mediates the phosphorylation of Mfn2, which is an important step in Parkin-mediated ubiquitination of Mfn2 [7,8,43,44]. However, the cause-and-effect link between activation of the pIRE1 $\alpha /$ XBP1s ER stress pathway and the downstream regulation of the PINK1/Parkin-mediated mitophagy pathway and reduced Mfn2 remains to be fully explored.

A
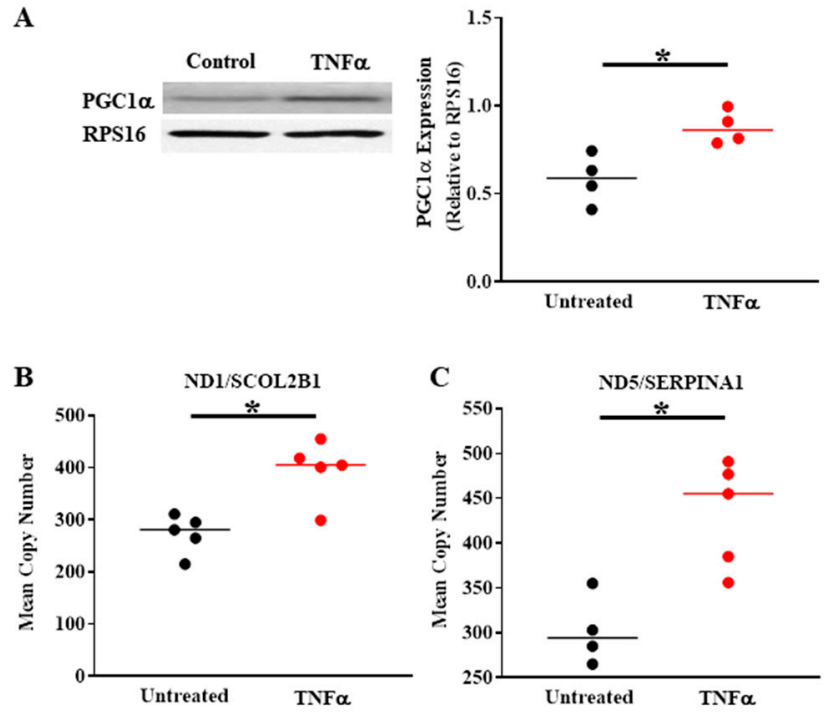

Figure 3. Compared to untreated controls, $\mathrm{TNF} \alpha(20 \mathrm{ng} / \mathrm{mL}, 24 \mathrm{~h})$ increases PGC1 $\alpha$ protein expression in human ASM (A) and mitochondrial DNA copy number $(\mathbf{B}, \mathbf{C})$, indicating an increase in mitochondrial biogenesis. ( ${ }^{*}$ denotes a significant difference between TNF $\alpha$ treated and untreated control groups; $p<0.05$; $t$-test; cells were dissociated from ASM samples from $n=5$ patients and divided into TNF $\alpha$ treated and untreated control groups). All data are presented as scatter plots with the lines indicating the mean values. These figures are modified from presentations of previously reported results [4].

In previous studies, we also observed that TNF $\alpha$ induces mitochondrial fragmentation in human ASM cells, which is consistent with a decrease in the mitochondrial fusion protein Mfn2 and an increase in the mitochondrial fission protein Drp1 [4]. The TNF $\alpha$-induced decrease in Mfn2 in ASM cells is dependent on activation of the pIRE1 $\alpha /$ XBP1s ER stress pathway, and likely relates to the PINK1/Parkin mitophagy pathway, as mentioned above. Based on our conceptual framework (Figure 1), we hypothesize that mitochondrial remodeling reflects a coordinated homeostatic response triggered by inflammation and TNF $\alpha$ exposure in human ASM cells. Another component of this homeostatic response involves an increase in mitochondrial biogenesis and mitochondrial volume density (Figure 3B,C) 
to cope with the excess ATP demand. With an increase in mitochondrial volume density, $\mathrm{O}_{2}$ consumption and the production of ATP would be shared across more mitochondria, thereby reducing ROS production by individual mitochondrion, and diminishing their risk for oxidative injury and cell death.

Mitochondria undergo continuous fusion and fission, which are essential for optimal mitochondrial function [45]. Three major proteins (i.e., mitofusins 1/2 (Mfn1/Mfn2), optic atrophy 1 (OPA1), and Drp1) balance the equilibrium between mitochondrial fusion and fission (Figure 4A), maintaining the functional activity of mitochondria when cells experience metabolic or environmental stress [45-47]. In a previous study, we found that exposing human ASM cells to cigarette smoke extract causes mitochondrial fragmentation by reducing Mfn2 and increasing Drp1 [48]. Recently, we found that acute exposure to $\mathrm{TNF} \alpha$ also induces a reduction in Mfn2 and an increase in Drp1 expression in human ASM cells (Figure 4B) with an associated mitochondrial fragmentation (Figure 4C,D) [4]. Mitochondria in human ASM cells were visualized by confocal imaging of MitoTracker labeling. Following 3D reconstruction, two specific mitochondrial morphological characteristics were calculated: (1) form factor, defined as the length of mitochondria ${ }^{2} / 4 \pi^{*}$ area of mitochondria (Figure 4C), and (2) aspect ratio, defined as the ratio of the major and minor axes of mitochondria (Figure 4D) [4]. Lower values of both form factor and aspect ratio indicate fragmentation (Figure 4C,D).

A
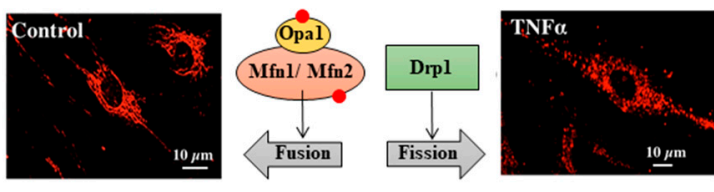

B Control TNF $\alpha$

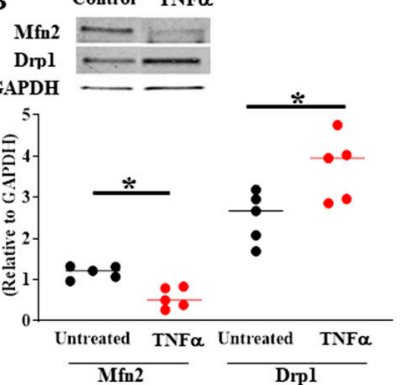

C

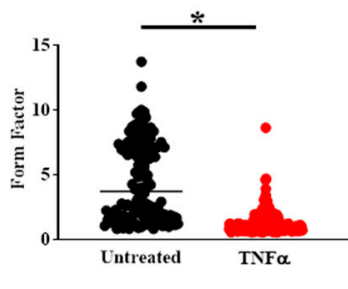

D

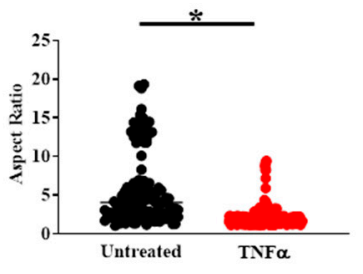

Figure 4. Compared to untreated controls, $\mathrm{TNF} \alpha(20 \mathrm{ng} / \mathrm{mL}, 24 \mathrm{~h})$ exposure induced mitochondrial fragmentation in human ASM (A) associated with reduced Mfn2 and increased Drp1 protein levels (B). The extent of mitochondrial fragmentation was assessed by calculating (C) form factor and (D) aspect ratio of mitochondria labeled using MitoTracker Red (A). In B, cells were dissociated from ASM samples from $n=5$ patients and divided into TNF $\alpha$ treated and untreated control groups. In $\mathrm{C}$ and $\mathrm{D}$, multiple mitochondria/cells were measured from ASM cells isolated from $n=5$ patients divided into TNF $\alpha$ treated and untreated control groups. (* denotes a significant difference between $\mathrm{TNF} \alpha$ treated and untreated control groups; $p<0.05$; $t$-test). All data are presented as scatter plots with lines indicating mean values. These figures are modified from presentations of previously reported results [4].

Previous studies have suggested that a reduction in Mfn2 and mitochondrial fragmentation are actually upstream of ER stress [49-52]. These studies in neurons, embryonic fibroblasts and Drosophila reported that Mfn2 knockdown activates the pIRE1 $\alpha /$ XBP1s ER stress pathway $[49,51,52]$. Consequently, these studies also suggested that a reduction in Mfn2 can alter the morphology of ER, as well as the proximity of mitochondria to the ER, thereby triggering ER stress [51,53]. However, our results in human ASM clearly indicate that the TNF $\alpha$-induced reduction in Mfn2 is downstream of the activation of the pIRE1 $\alpha /$ XBP1s ER stress pathway [3]; however, this does not preclude a vicious cycle that would amplify oxidative stress and cell injury unless mitigated by a homeostatic response. 


\section{TNF $\alpha$-Induced Reduction in Mfn2 Disrupts Mitochondrial Tethering to ER and Reduces Mitochondrial $\mathrm{Ca}^{2+}$ Influx}

In ASM, the TNF $\alpha$-induced increase in force and ATP consumption stimulates F1FoATPase/ATP synthase (complex V) activity and increases $\mathrm{O}_{2}$ consumption and ATP production in mitochondria. Based on biochemical studies, it is well known that mitochondrial production of ATP (oxidative phosphorylation) also depends on dehydrogenase enzyme activities of the TCA cycle, particularly pyruvate dehydrogenase (PDH), NAD-isocitrate dehydrogenase $(\mathrm{ICDH})$, and oxoglutarate dehydrogenase $(\mathrm{OGDH})$, which are $\mathrm{Ca}^{2+} \mathrm{de}-$ pendent [54-58]. Additionally, an increase in $\left[\mathrm{Ca}^{2+}\right]_{\text {cyt }}$ increases NADH levels in the mitochondria by stimulating mitochondrial shuttle systems such as the glycerol phosphate shuttle and the aspartate/glutamate transporters [59-61]. Thus, mitochondrial $\mathrm{Ca}^{2+}$ influx during transient elevation of $\left[\mathrm{Ca}^{2+}\right]_{\mathrm{cyt}}$ stimulates dehydrogenase enzyme activities within the TCA cycle and increases $\mathrm{O}_{2}$ consumption, electron transport chain (ETC) flux and ATP production through excitation-energy coupling (Figure 2). Conversely, it is well known that increased ATP consumption leads to transport of ADP into mitochondria via the adenosine nucleotide transporter (ANT), which stimulates F1Fo-ATPase/ATP synthase (complex V) activity [62] to match ATP production with ATP consumption (Figure 2). Together, the excitation-contraction mediated ATP hydrolysis and subsequent production of ATP by ATP synthase ultimately forms a normal homeostatic mechanism that we termed excitationenergy coupling in a variety of cell types including human ASM $[9,10,63]$. Pathophysiology, such as airway inflammation and mitochondrial dysfunction, involves disruptions in these mitochondrial energy-sensing/signaling pathways. Furthermore, a consistent elevation in $\left[\mathrm{Ca}^{2+}\right]_{\mathrm{mit}}$ can trigger the opening of mPTP and ultimately can lead to mitochondrial dysfunction and cellular death $[35,36]$. In previous studies in ASM cells, we showed that the transient $\left[\mathrm{Ca}^{2+}\right]_{\mathrm{cyt}}$ response to $1 \mu \mathrm{M}$ ACh stimulation is accompanied by a transient elevation of $\left[\mathrm{Ca}^{2+}\right]_{\text {mito }}[9,13,64]$ and we confirmed that the transient $\left[\mathrm{Ca}^{2+}\right]_{\text {mito }}$ response was inhibited by blocking the mitochondrial $\mathrm{Ca}^{2+}$ uniporter (MCU). Mitochondrial $\mathrm{Ca}^{2+}$ influx via the MCU is only activated by microdomains of higher $\left[\mathrm{Ca}^{2+}\right]_{\mathrm{cyt}}($ "hotspots" $>2 \mu \mathrm{M}$ ) [9-12], which exceed the normal global transient $\left[\mathrm{Ca}^{2+}\right]_{\mathrm{cyt}}$ response to agonist stimulation in ASM ( 500-600 nM). Higher levels of $\left[\mathrm{Ca}^{2+}\right]_{\text {cyt }}$ are present at the ER Ca ${ }^{2+}$ release sites ( $\mathrm{IP}_{3}$ and RyR channels). Thus, during agonist stimulation, mitochondria must be tethered to the ER to provide close proximity to $\left[\mathrm{Ca}^{2+}\right]_{\mathrm{cyt}}$ "hotspots" in order to activate the MCU for mitochondrial $\mathrm{Ca}^{2+}$ influx. Although TNF $\alpha$ exposure increases the $\left[\mathrm{Ca}^{2+}\right]_{\text {cyt }}$ response to $\mathrm{ACh}$ in ASM cells, the $\left[\mathrm{Ca}^{2+}\right]_{\text {mito }}$ response is markedly reduced [64], reflecting a decrease in mitochondrial $\mathrm{Ca}^{2+}$ influx. Recent studies have shown that TNF $\alpha$ exposure reduces the motility of mitochondria and disrupts the tethering of mitochondria to ER, thereby affecting the proximity of mitochondria to $\left[\mathrm{Ca}^{2+}\right]_{\text {cyt }}$ "hotspots" (Figure 5) [13]. This disruption of mitochondrial/ER proximity results in reduced MCU activation and a decrease in transient mitochondrial $\mathrm{Ca}^{2+}$ influx during agonist activation. The reduction in mitochondrial $\mathrm{Ca}^{2+}$ concentration $\left(\left[\mathrm{Ca}^{2+}\right]_{\text {mito }}\right)$ following acute TNF $\alpha$ exposure subsequently reduces TCA cycle activity, $\mathrm{O}_{2}$ consumption and ROS formation (Figure 2) [13,64]. $\mathrm{TNF} \alpha$ exposure reduced proximity of mitochondria to the ER, which is also consistent with the uncoupling of transient $\left[\mathrm{Ca}^{2+}\right]_{\mathrm{cyt}}$ and $\left[\mathrm{Ca}^{2+}\right]_{\text {mito }}$ responses to agonist stimulation due to an inability to establish hot spots for mitochondrial $\mathrm{Ca}^{2+}$ influx via the MCU. 
A
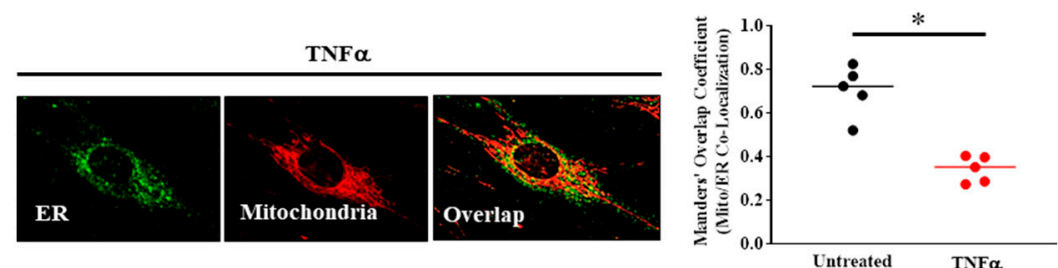

B

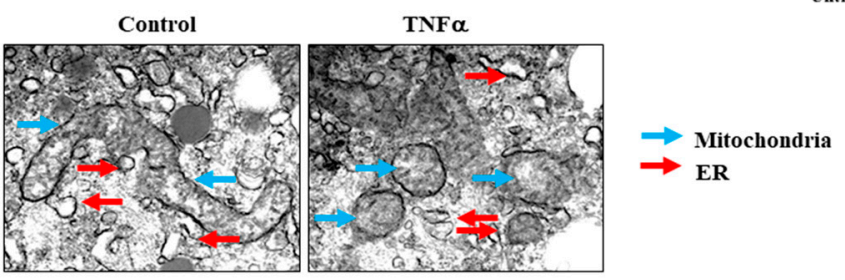

Figure 5. (A) In human ASM cells, ER was labeled using BODIPY FL thapsigargin (endoplasmic reticulum $\mathrm{Ca}^{2+}$ pumps, green) and mitochondria were labeled using MitoTracker red and imaged in $3 \mathrm{D}$ by confocal microscopy. Proximity of mitochondria to the ER was determined by measuring the Manders' overlap co-efficient. Acute TNF $\alpha$ exposure $(20 \mathrm{ng} / \mathrm{mL}, 24 \mathrm{~h})$ reduced proximity of mitochondria to the ER ( ${ }^{*}$ denotes a significant difference between TNF $\alpha$ treated and untreated control groups; $p<0.05$; $t$-test; cells were dissociated from ASM samples from $n=5$ patients and divided into $\mathrm{TNF} \alpha$ treated and untreated control groups). (B) 3D EM images showing that mitochondria (blue arrows) in human ASM cells are fragmented after TNF $\alpha$ (20 ng/mL, $24 \mathrm{~h})$ exposure and that the incidence of close proximity of mitochondria to ER (red arrows) was reduced (cells were dissociated from ASM samples from $n=2$ patients and divided into TNF $\alpha$ treated and untreated control groups). All data are presented as scatter plots with lines indicating the mean. These figures are modified from presentations of previously reported results [13].

The disruption of proximity of mitochondria in ASM cells induced by acute TNF $\alpha$ is likely due to the reduction in Mfn2. Mfn2 is located at the ER membrane and dimerizes with Mfn2 (Mfn2/Mfn2) and/or Mfn1 (Mfn1/Mfn2) located at the mitochondrial membrane, and thereby plays an essential role in tethering mitochondria to the ER [9-12,53,58,65]. In a published study from our lab [13], mitochondrial proximity to the ER was assessed using fluorescent labeling of the ER and mitochondria, confocal imaging and 3D reconstruction and overlap areas were estimated using the Manders' overlap coefficient (Figure 5A). We found that acute TNF $\alpha$ exposure markedly reduced the proximity of mitochondria to the ER (Figure 5A) [13]. The proximity of mitochondria to the ER was also assessed using 3D EM (Figure 5B). Consistent with results from confocal imaging (Figure 4C,D) [4], we found that mitochondria in human ASM cells were fragmented after $24 \mathrm{~h}$ exposure to TNF $\alpha$ (Figure 5B) [13].

In addition, the mitochondrial proximity to the ER was reduced. In addition to Mfn2 mediated tethering, TNF $\alpha$ exposure also disrupts basal mitochondrial movement by reducing the expression of two mitochondrial motility associated proteins: miro (mitochondrial Rho GTPase protein, also called RhoT1/2) and milton (a trafficking protein kinesin, TRAK) [13]. These two proteins help in the coupling of mitochondria with microtubules and maintain the directed trajectory or kinetic, more random motion of mitochondria, which is necessary to establish a proximity to the ER (or $\mathrm{Ca}^{2+}$ hotspots) [66]. Thereby disrupting the ability of mitochondria to establish proximity to the ER, TNF $\alpha$ reduces the transient mitochondrial $\mathrm{Ca}^{2+}$ uptake during agonist activation and ultimately reduces the $\mathrm{O}_{2}$ consumption and oxidative phosphorylation for each mitochondrion.

\section{TNF $\alpha$-Induced Mitochondrial Biogenesis and Increased Volume Density Increases $\mathrm{O}_{2}$ Consumption and ATP Production While Mitigating ROS Formation}

Previous studies have shown that TNF $\alpha$ exposure increases mitochondrial $\mathrm{O}_{2}$ consumption rate in ASM (Figure 6) [4]. However, TNF $\alpha$ also increases mitochondrial volume density in ASM cells (Figure 6A,B) [4]. As a result, when corrected for the increase in mitochondrial volume, $\mathrm{O}_{2}$ consumption rate per mitochondrion is reduced (Figure 6C,D) [4]. 
Underlying the TNF $\alpha$-induced increase in mitochondrial volume density, we found that mitochondrial biogenesis was increased as reflected by an increase in DNA copy number (Figure 3B,C). Interestingly, studies have reported that mitochondrial biogenesis is also enhanced in asthmatic ASM [67,68]; however, these studies did not examine mitochondrial network morphology or the mechanisms mediating mitochondrial biogenesis. An increase in mitochondrial volume density is an alternative mechanism to increase overall cellular $\mathrm{O}_{2}$ consumption and ATP production to meet the increased ATP demand in human ASM after exposure to pro-inflammatory cytokines. However, as a result of the increase in mitochondrial volume, the $\mathrm{O}_{2}$ consumption per mitochondrion is reduced (Figure 6D), thereby minimizing formation of ROS per mitochondrion (Figure 6F). With the overall increase in $\mathrm{O}_{2}$ consumption in ASM cells induced by TNF $\alpha$, ROS formation also increases (Figure 6E) [3]. It should be noted again that TNF $\alpha$ also increases mitochondrial biogenesis and volume density in human ASM (Figure 6A,B). Thus, when the TNF $\alpha$-induced ROS formation was normalized for mitochondrial volume density, ROS formation per mitochondrion was mitigated (Figure 6F). This increase in mitochondrial volume is a possible homeostatic response to maintain the increased ATP production while reducing the impact of $\mathrm{O}_{2}$ consumption and ROS formation per mitochondrion, and overall scavenging (by SOD, etc.) would be more effective.
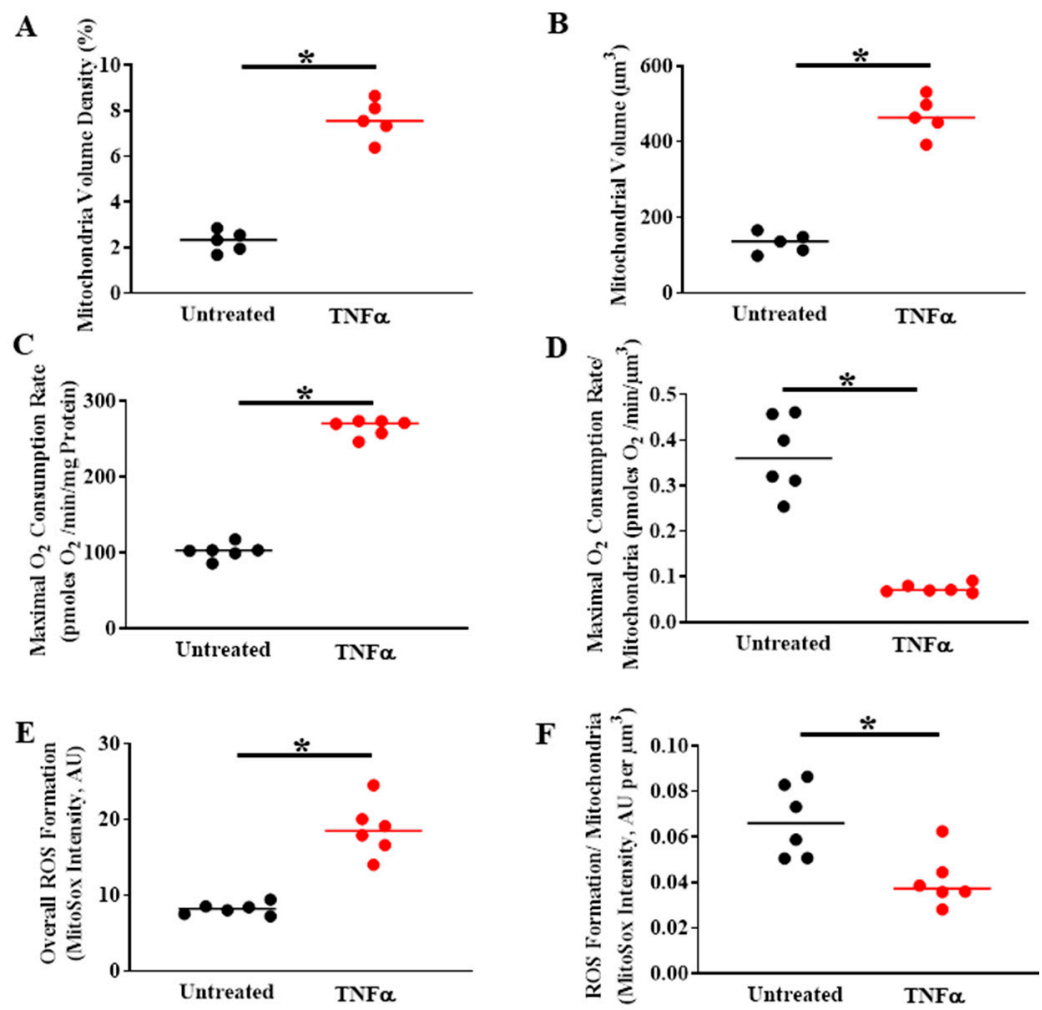

Figure 6. In human ASM cells, $\mathrm{TNF} \alpha$ exposure $(20 \mathrm{ng} / \mathrm{mL}, 24 \mathrm{~h})$ increases (A) mitochondrial volume density per cell and (B) and the total mitochondrial volume and (C) overall maximum mitochondrial $\mathrm{O}_{2}$ consumption rate (measured using Seahorse) (D) maximum $\mathrm{O}_{2}$ consumption rate when normalized for mitochondrial volume density, $\mathrm{O}_{2}$ consumption rate per mitochondrion (i.e., normalized for) is reduced; (E) overall ROS formation measured using MitoSox; (F) however, when normalized for mitochondrial volume density, this increase in ROS is mitigated. (* denotes a significant difference between TNF $\alpha$ treated and untreated control groups; $p<0.05$; $t$-test; cells were dissociated from ASM samples from $n=5$ patients and divided into TNF $\alpha$ treated and untreated control groups). All data are presented as scatter plots with the lines indicating the mean values. These figures are modified from presentations of previously reported results [4]. 


\section{The Homeostatic Response to TNF $\alpha$ in Asthmatic Human ASM}

Asthma is a chronic inflammatory condition of ASM, characterized by airway inflammation, airway hyper-contractility and airway remodeling (ASM proliferation) [69-73]. Surprisingly, very few studies on asthma have dealt with the crosstalk between mitochondrial oxidative stress and ER stress response and its impact on the inflammation in human ASM to date. An increased ROS generation is reported in asthmatic patients $[69,74,75]$, which can trigger the ER stress in human ASM. Some studies have demonstrated that the activation of ER stress response in airway epithelial cells or immune cells is enhanced in asthma [19-21] but did not specifically explore the contribution of any of the ER stress sensor activation in this context. However, to date, no study has explored the impact of ER stress and its marker activation in human asthmatic ASM. As mentioned above, proinflammatory cytokine TNF $\alpha$ selectively induces the pIRE1 $\alpha /$ XBP1s ER stress pathway in non-asthmatic ASM [3], and the effect of inflammation is not explored in asthmatic ASM. It is not known whether TNF $\alpha$ mediated ER stress plays a similar homeostatic role maintaining the dynamicity and activity of mitochondria in asthmatic conditions or if the effect is blunted. Additionally, the impact of any other proinflammatory cytokines other than TNF $\alpha$ in asthma is also a question to be answered. Previous studies have shown that in asthmatic ASM, mitochondrial biogenesis is increased [67,68], and we can speculate that it can be positively correlated with mitochondrial volume density, however, it has not been reported so far. We have reported an increase in mitochondrial fragmentation in human ASM of moderate asthmatics associated with an increase in mitochondrial fission protein Drp1 and a decrease in fusion protein Mfn2 expression in asthma, resulting in more fragmented mitochondrial networks [48]. Considering all the experimental evidence, further illustrating studies are needed to understand the impact of inflammation on ER stress and mitochondrial crosstalk in asthma and also to find some novel therapeutic target(s).

\section{Conclusions}

With the recent emergence of the COVID-19 pandemic, we became concerned with the pathological significance of acute airway inflammation, which is mediated by proinflammatory cytokines (e.g., TNF $\alpha$ ). TNF $\alpha$ plays a major role in force generation and ATP consumption by ASM during airway inflammation and induces mitochondrial oxidative phosphorylation to match the increased ATP demand. As a result, ROS generation and oxidative stress is increased, which can be deleterious to the system. Simultaneously, as a homeostatic response, TNF $\alpha$ selectively activates the pIRE1 $\alpha / \mathrm{XBP} 1 \mathrm{~s}$ mediated ER stress pathway in ASM and increases mitochondrial biogenesis and mitochondrial volume density and reduces $\mathrm{O}_{2}$ consumption and ROS formation by individual mitochondrion and protects ASM cells from the negative impact of inflammation-induced ROS formation while still meeting the ATP demand. In our belief, a failure in this homeostatic mechanism can lead to increased ROS formation, thereby exacerbating cell death.

Author Contributions: Writing-original draft preparation, D.D., P.D. and G.C.S.; writing-review and editing, D.D., P.D. and G.C.S. All authors have read and agreed to the published version of the manuscript.

Funding: This research received no external funding.

Conflicts of Interest: The authors declare no conflict of interest.

$\begin{array}{ll}\text { Abbreviations } \\ \text { ACh } & \text { acetylcholine } \\ \text { ASM } & \text { airway smooth muscle cells } \\ \text { ATF6 } & \text { activating transcription factor } 6 \\ \text { Drp1 } & \text { dynamin-related protein-1 } \\ \text { IRE1 } \alpha & \text { inositol-requiring enzyme 1 } \\ \text { MCU } & \text { mitochondrial } \mathrm{Ca}^{2+} \text { uniporter } \\ \text { Mfn2 } & \text { mitofusin-2 }\end{array}$




$\begin{array}{ll}\text { rMLC }_{20} & \text { regulatory myosin light chain } \\ \text { MLCK } & \text { myosin light chain kinase } \\ \text { mtUPR } & \text { mitochondrial unfolded protein response } \\ \text { MyHC } & \text { myosin heavy chain } \\ \text { protein kinase RNA-like ER kinase } \\ \text { PERK } & \begin{array}{l}\text { peroxisome proliferator-activated } \\ \text { receptor-gamma coactivator } 1 \text { alpha }\end{array} \\ \text { PGC1 } \alpha & \text { PTEN-induced putative kinase 1 } \\ \text { PINK1 } & \text { reactive oxygen species } \\ \text { ROS } & \text { X-box protein } 1\end{array}$

\section{References}

1. Dogan, M.; Han, Y.S.; Delmotte, P.; Sieck, G.C. TNFalpha enhances force generation in airway smooth muscle. Am. J. Physiol. Lung Cell Mol. Physiol. 2017, 312, L994-L1002. [CrossRef]

2. Sieck, G.C.; Dogan, M.; Young-Soo, H.; Osorio Valencia, S.; Delmotte, P. Mechanisms underlying TNFalpha-induced enhancement of force generation in airway smooth muscle. Physiol. Rep. 2019, 7, e14220. [CrossRef]

3. Yap, J.; Chen, X.; Delmotte, P.; Sieck, G.C. TNF $\alpha$ selectively activates the IRE1 $\alpha /$ XBP1 endoplasmic reticulum stress pathway in human airway smooth muscle cells. Am. J. Physiol. Lung Cell Mol. Physiol. 2020, 318, L483-1493. [CrossRef]

4. Delmotte, P.F.; Marin Mathieu, N.; Sieck, G.C. TNF $\alpha$ Induces Mitochondrial Fragmentation and Biogenesis in Human Airway Smooth Muscle. Am. J. Physiol. Lung. Cell Mol. Physiol. 2020. [CrossRef] [PubMed]

5. Münch, C. The different axes of the mammalian mitochondrial unfolded protein response. BMC Biol. 2018, 16, 81. [CrossRef] [PubMed]

6. Münch, C.; Harper, J.W. Mitochondrial unfolded protein response controls matrix pre-RNA processing and translation. Nature 2016, 534, 710-713. [CrossRef]

7. Basso, V.; Marchesan, E.; Peggion, C.; Chakraborty, J.; von Stockum, S.; Giacomello, M.; Ottolini, D.; Debattisti, V.; Caicci, F.; Tasca, E.; et al. Regulation of ER-mitochondria contacts by Parkin via Mfn2. Pharmacol. Res. 2018, 138, 43-56. [CrossRef]

8. McLelland, G.L.; Goiran, T.; Yi, W.; Dorval, G.; Chen, C.X.; Lauinger, N.D.; Krahn, A.I.; Valimehr, S.; Rakovic, A.; Rouiller, I.; et al. Mfn2 ubiquitination by PINK1/parkin gates the p97-dependent release of ER from mitochondria to drive mitophagy. Elife 2018, 7, e32866. [CrossRef]

9. Delmotte, P.; Sieck, C.G. Interaction between endoplasmic/sarcoplasmic reticulum stress (ER/SR stress), mitochondrial signaling and $\mathrm{Ca}(2+)$ regulation in airway smooth muscle (ASM). Can. J. Physiol. Pharmacol. 2015, 93, 97-110. [CrossRef]

10. Delmotte, P.; Sieck, C.G. Endoplasmic reticulum stress and mitochondrial function in airway smooth muscle. Front. Cell Dev. Biol. 2020, 7, 374. [CrossRef]

11. Giacomello, M.; Drago, I.; Bortolozzi, M.; Scorzeto, M.; Gianelle, A.; Pizzo, P.; Pozzan, T. Ca ${ }^{2+}$ hot spots on the mitochondrial surface are generated by $\mathrm{Ca}^{2+}$ mobilization from stores, but not by activation of store-operated $\mathrm{Ca}^{2+}$ channels. Mol. Cell. 2010, 38, 280-290. [CrossRef]

12. Pallafacchina, G.; Zanin, S.; Rizzuto, R. Recent advances in the molecular mechanism of mitochondrial calcium uptake. F1000Research 2018, 7. [CrossRef] [PubMed]

13. Delmotte, P.; Zavaletta, V.A.; Thompson, M.A.; Prakash, Y.S.; Sieck, G.C. TNFalpha decreases mitochondrial movement in human airway smooth muscle. Am. J. Physiol. Lung Cell Mol. Physiol. 2017, 313, L166-L176. [CrossRef] [PubMed]

14. Murphy, R.A.; Gerthoffer, W.T.; Trevethick, M.A.; Singer, H.A. Ca ${ }^{2+}$-dependent regulatory mechanisms in smooth muscle. Bibl. Cardiol. 1984, 38, 99-107.

15. Sieck, G.C.; Gransee, H.M. Respiratory muscles structure, function \& regulation. In Colloquium Series on Integrated Systems Physiology, from Molecule to Function to Disease; Morgan \& Claypool: San Rafael, CA, USA, 2012; p. 87.

16. Sieck, G.C.; Han, Y.S.; Prakash, Y.S.; Jones, K.A. Cross-bridge cycling kinetics, actomyosin ATPase activity and myosin heavy chain isoforms in skeletal and smooth respiratory muscles. Comp. Biochem. Physiol. B Biochem. Mol. Biol. 1998, 119, 435-450. [CrossRef]

17. Squire, J. The actin-myosin interaction in muscle: Background and overview. Int. J. Mol. Sci. 2019, 20, 5715. [CrossRef]

18. DuRose, J.B.; Tam, A.B.; Niwa, M. Intrinsic capacities of molecular sensors of the unfolded protein response to sense alternate forms of endoplasmic reticulum stress. Mol. Biol. Cell. 2006, 17, 3095-3107. [CrossRef]

19. Kim, S.R.; Lee, Y. Endoplasmic reticulum stress and the related signaling networks in severe asthma. Allergy Asthma Immunol. Res. 2015, 7, 106-117. [CrossRef] [PubMed]

20. Jeong, J.S.; Kim, S.R.; Cho, S.H.; Lee, Y.C. Endoplasmic reticulum stress and allergic diseases. Curr. Allergy Asthma Rep. 2017, 17, 82. [CrossRef]

21. Pathinayake, P.S.; Hsu, A.C.; Waters, D.W.; Hansbro, P.M.; Wood, L.G.; Wark, P.A.B. Understanding the unfolded protein response in the pathogenesis of asthma. Front. Immunol. 2018, 9, 175. [CrossRef]

22. Siddesha, J.M.; Nakada, E.M.; Mihavics, B.R.; Hoffman, S.M.; Rattu, G.K.; Chamberlain, N.; Cahoon, J.M.; Lahue, K.G.; Daphtary, N.; Aliyeva, M.; et al. Effect of a chemical chaperone, tauroursodeoxycholic acid, on HDM-induced allergic airway disease. Am. J. Physiol. Lung Cell Mol. Physiol. 2016, 310, L1243-L1259. [CrossRef] [PubMed] 
23. Miller, M.; Rosenthal, P.; Beppu, A.; Mueller, J.L.; Hoffman, H.M.; Tam, A.B.; Doherty, T.A.; McGeough, M.D.; Pena, C.A.; Suzukawa, M.; et al. ORMDL3 transgenic mice have increased airway remodeling and airway responsiveness characteristic of asthma. J. Immunol. 2014, 192, 3475-3487. [CrossRef] [PubMed]

24. Kim, S.R.; Kim, D.I.; Kang, M.R.; Lee, K.S.; Park, S.Y.; Jeong, J.S.; Lee, Y.C. Endoplasmic reticulum stress influences bronchial asthma pathogenesis by modulating nuclear factor kappaB activation. J. Allergy Clin. Immunol. 2013, 132, 1397-1408. [CrossRef] [PubMed]

25. Makhija, L.; Krishnan, V.; Rehman, R.; Chakraborty, S.; Maity, S.; Mabalirajan, U.; Chakraborty, K.; Ghosh, B.; Agrawal, A. Chemical chaperones mitigate experimental asthma by attenuating endoplasmic reticulum stress. Am. J. Respir. Cell Mol. Biol. 2014, 50, 923-931. [CrossRef] [PubMed]

26. Shpilka, T.; Haynes, C.M. The mitochondrial UPR: Mechanisms, physiological functions and implications in ageing. Nat. Rev. Mol. Cell. Biol. 2018, 19, 109-120. [CrossRef]

27. Pakos-Zebrucka, K.; Koryga, I.; Mnich, K.; Ljujic, M.; Samali, A.; Gorman, A.M. The integrated stress response. EMBO Rep. 2016, 17, 1374-1395. [CrossRef]

28. Teske, B.F.; Fusakio, M.E.; Zhou, D.; Shan, J.; McClintick, J.N.; Kilberg, M.S.; Wek, R.C. CHOP induces activating transcription factor 5 (ATF5) to trigger apoptosis in response to perturbations in protein homeostasis. Mol. Biol. Cell 2013, 24, 2477-2490. [CrossRef]

29. Fusakio, M.E.; Willy, J.A.; Wang, Y.; Mirek, E.T.; Al Baghdadi, R.J.; Adams, C.M.; Anthony, T.G.; Wek, R.C. Transcription factor ATF4 directs basal and stress-induced gene expression in the unfolded protein response and cholesterol metabolism in the liver. Mol. Biol. Cell. 2016, 27, 1536-1551. [CrossRef]

30. Yung, H.W.; Colleoni, F.; Dommett, E.; Cindrova-Davies, T.; Kingdom, J.; Murray, A.J.; Burton, G.J. Noncanonical mitochondrial unfolded protein response impairs placental oxidative phosphorylation in early-onset preeclampsia. Proc. Natl. Acad. Sci. USA 2019, 116, 18109-18118. [CrossRef]

31. Qureshi, M.A.; Haynes, C.M.; Pellegrino, M.W. The mitochondrial unfolded protein response: Signaling from the powerhouse. J. Biol. Chem. 2017, 292, 13500-13506. [CrossRef]

32. Rasola, A.; Bernardi, P. The mitochondrial permeability transition pore and its involvement in cell death and in disease pathogenesis. Apoptosis 2007, 12, 815-833. [CrossRef] [PubMed]

33. Müller, M.; Ahumada-Castro, U.; Sanhueza, M.; Gonzalez-Billault, C.; Court, F.A.; Cárdenas, C. Mitochondria and calcium regulation as basis of neurodegeneration associated with aging. Front. Neurosci. 2018, 12, 470. [CrossRef] [PubMed]

34. Ichas, F.; Jouaville, L.S.; Mazat, J.P. Mitochondria are excitable organelles capable of generating and conveying electrical and calcium signals. Cell 1997, 89, 1145-1153. [CrossRef]

35. Bauer, T.M.; Murphy, E. Role of mitochondrial calcium and the permeability transition pore in regulating Cell Death. Circ. Res. 2020, 126, 280-293. [CrossRef]

36. Bernardi, P.; Di Lisa, F. The mitochondrial permeability transition pore: Molecular nature and role as a target in cardioprotection. J. Mol. Cell Cardiol. 2015, 78, 100-106. [CrossRef]

37. Rottenberg, H.; Hoek, J.B. The path from mitochondrial ROS to aging runs through the mitochondrial permeability transition pore. Aging Cell 2017, 16, 943-955. [CrossRef]

38. Corona, J.C.; Duchen, M.R. PPAR $\gamma$ and PGC-1 $\alpha$ as therapeutic targets in Parkinson's. Neurochem. Res. 2015, 40, 308-316. [CrossRef]

39. Jamwal, S.; Blackburn, J.K.; Elsworth, J.D. PPAR $\gamma /$ PGC1 $\alpha$ signaling as a potential therapeutic target for mitochondrial biogenesis in neurodegenerative disorders. Pharmacol. Ther. 2020, 107705. [CrossRef]

40. Corona, J.C.; Duchen, M.R. PPAR $\gamma$ as a therapeutic target to rescue mitochondrial function in neurological disease. Free Radic. Biol. Med. 2016, 100, 153-163. [CrossRef]

41. Arensdorf, A.M.; Diedrichs, D.; Rutkowski, D.T. Regulation of the transcriptome by ER stress: Non-canonical mechanisms and physiological consequences. Front. Genet. 2013, 4, 256. [CrossRef]

42. Quinn, P.M.J.; Moreira, P.I.; Ambrósio, A.F.; Alves, C.H. PINK1/PARKIN signalling in neurodegeneration and neuroinflammation. Acta Neuropathol. Commun. 2020, 8, 189. [CrossRef] [PubMed]

43. Chen, Y.; Dorn, G.W. PINK1-phosphorylated mitofusin 2 is a Parkin receptor for culling damaged mitochondria. Science 2013, 340, 471-475. [CrossRef] [PubMed]

44. Leites, E.P.; Morais, V.A. Mitochondrial quality control pathways: PINK1 acts as a gatekeeper. Biochem. Biophys. Res. Commun. 2018, 500, 45-50. [CrossRef] [PubMed]

45. Chan, D.C. Mitochondrial fusion and fission in mammals. Annu. Rev. Cell Dev. Biol. 2006, 22, 79-99. [CrossRef] [PubMed]

46. Chandhok, G.; Lazarou, M.; Neumann, B. Structure, function, and regulation of mitofusin-2 in health and disease. Biol. Rev. Camb. Philos. Soc. 2018, 93, 933-949. [CrossRef] [PubMed]

47. Dorn, G.W.; Kitsis, R.N. The mitochondrial dynamism-mitophagy-cell death interactome: Multiple roles performed by members of a mitochondrial molecular ensemble. Circ. Res. 2015, 116, 167-182. [CrossRef] [PubMed]

48. Aravamudan, B.; Kiel, A.; Freeman, M.; Delmotte, P.; Thompson, M.; Vassallo, R.; Sieck, G.C.; Pabelick, C.M.; Prakash, Y.S. Cigarette smoke-induced mitochondrial fragmentation and dysfunction in human airway smooth muscle. Am. J. Physiol. Lung Cell Mol. Physiol. 2014, 306, L840-L854. [CrossRef] 
49. Bhandari, P.; Song, M.; Dorn, G.W. Dissociation of mitochondrial from sarcoplasmic reticular stress in Drosophila cardiomyopathy induced by molecularly distinct mitochondrial fusion defects. J. Mol. Cell Cardiol. 2015, 80, 71-80. [CrossRef]

50. Muñoz, J.P.; Ivanova, S.; Sánchez-Wandelmer, J.; Martínez-Cristóbal, P.; Noguera, E.; Sancho, A.; Díaz-Ramos, A.; HernándezAlvarez, M.I.; Sebastián, D.; Mauvezin, C.; et al. Mfn2 modulates the UPR and mitochondrial function via repression of PERK. EMBO J. 2013, 32, 2348-2361. [CrossRef]

51. Ngoh, G.A.; Papanicolaou, K.N.; Walsh, K. Loss of mitofusin 2 promotes endoplasmic reticulum stress. J. Biol. Chem. 2012, 287, 20321-20332. [CrossRef]

52. Schneeberger, M.; Dietrich, M.O.; Sebastián, D.; Imbernón, M.; Castaño, C.; Garcia, A.; Esteban, Y.; Gonzalez-Franquesa, A.; Rodríguez, I.C.; Bortolozzi, A.; et al. Mitofusin 2 in POMC neurons connects ER stress with leptin resistance and energy imbalance. Cell 2013, 155, 172-187. [CrossRef] [PubMed]

53. Filadi, R.; Theurey, P.; Pizzo, P. The endoplasmic reticulum-mitochondria coupling in health and disease: Molecules, functions and significance. Cell Calcium. 2017, 62, 1-15. [CrossRef] [PubMed]

54. Franzini-Armstrong, C. ER-mitochondria communication. How privileged? Physiology 2007, 22, 261-268. [CrossRef] [PubMed]

55. Maack, C.; O'Rourke, B. Excitation-contraction coupling and mitochondrial energetics. Basic Res. Cardiol. 2007, 102, 369-392. [CrossRef] [PubMed]

56. Gherardi, G.; Monticelli, H.; Rizzuto, R.; Mammucari, C. The Mitochondrial Ca(2+) Uptake and the Fine-Tuning of Aerobic Metabolism. Front. Physiol. 2020, 11, 554904. [CrossRef] [PubMed]

57. Vallese, F.; Barazzuol, L.; Maso, L.; Brini, M.; Calì, T. ER-Mitochondria calcium transfer, organelle contacts and neurodegenerative diseases. Adv. Exp. Med. Biol. 2020, 1131, 719-746.

58. Fan, Y.; Simmen, T. Mechanistic connections between endoplasmic reticulum (ER) redox control and mitochondrial metabolism. Cells 2019, 8, 1071. [CrossRef]

59. Palmieri, L.; Pardo, B.; Lasorsa, F.M.; del Arco, A.; Kobayashi, K.; Iijima, M.; Runswick, M.; Walker, J.E.; Saheki, T.; Satrústegui, J.; et al. Citrin and aralar1 are $\mathrm{Ca}(2+)$-stimulated aspartate/glutamate transporters in mitochondria. EMBO J. 2001, 20, 5060-5069. [CrossRef]

60. Amoedo, N.D.; Punzi, G.; Obre, E.; Lacombe, D.; De Grassi, A.; Pierri, C.L.; Rossignol, R. AGC1/2, the mitochondrial aspartateglutamate carriers. Biochim. Biophys. Acta 2016, 1863, 2394-2412. [CrossRef]

61. Rueda, C.B.; Llorente-Folch, I.; Traba, J.; Amigo, I.; Gonzalez-Sanchez, P.; Contreras, L.; Juaristi, I.; Martinez-Valero, P.; Pardo, B.; Del Arco, A.; et al. Glutamate excitotoxicity and Ca2+-regulation of respiration: Role of the Ca2+ activated mitochondrial transporters (CaMCs). Biochim. Biophys. Acta 2016, 1857, 1158-1166. [CrossRef]

62. Ruprecht, J.J.; Kunji, E.R. Structural changes in the transport cycle of the mitochondrial ADP/ATP carrier. Curr. Opin. Struct. Biol. 2019, 57, 135-144. [CrossRef] [PubMed]

63. Schaible, N.; Delmotte, P.; Sieck, G.C. Mitochondrial Excitation-Energy Coupling in Airway Smooth Muscle. In Mitochondrial Function in Lung Health and Disease; Natarajan, V., Parinandi, N.L., Eds.; Humana Press Inc.: Totowa, NJ, USA, 2014; pp. 93-116.

64. Delmotte, P.; Yang, B.; Thompson, M.A.; Pabelick, C.M.; Prakash, Y.S.; Sieck, G.C. Inflammation alters regional mitochondrial calcium in human airway smooth muscle cells. Am. J. Physiol. Cell Physiol. 2012, 303, C244-C256. [CrossRef]

65. Lee, S.; Min, K.T. The interface between ER and mitochondria: Molecular compositions and functions. Mol. Cells 2018, 41, 1000-1007. [PubMed]

66. Facts about chickenpox. Paediatr. Child. Health 2005, 10, 413-414. [CrossRef] [PubMed]

67. Girodet, P.O.; Ozier, A.; Bara, I.; Tunon de Lara, J.M.; Marthan, R.; Berger, P. Airway remodeling in asthma: New mechanisms and potential for pharmacological intervention. Pharmacol. Ther. 2011, 130, 325-337. [CrossRef] [PubMed]

68. Trian, T.; Benard, G.; Begueret, H.; Rossignol, R.; Girodet, P.O.; Ghosh, D.; Ousova, O.; Vernejoux, J.M.; Marthan, R.; Tunon-deLara, J.M.; et al. Bronchial smooth muscle remodeling involves calcium-dependent enhanced mitochondrial biogenesis in asthma. J. Exp. Med. 2007, 204, 3173-3181. [CrossRef] [PubMed]

69. Athari, S.S. Targeting cell signaling in allergic asthma. Signal. Transduct. Target. Ther. 2019, 4, 45. [CrossRef]

70. Alashkar Alhamwe, B.; Miethe, S.; Pogge von Strandmann, E.; Potaczek, D.P.; Garn, H. Epigenetic regulation of airway epithelium immune functions in asthma. Front. Immunol. 2020, 11, 1747. [CrossRef]

71. Rosanna, D.P.; Salvatore, C. Reactive oxygen species, inflammation, and lung diseases. Curr. Pharm. Des. 2012, 18, 3889-3900. [CrossRef] [PubMed]

72. Hough, K.P.; Curtiss, M.L.; Blain, T.J.; Liu, R.M.; Trevor, J.; Deshane, J.S.; Thannickal, V.J. Airway remodeling in asthma. Front. Med. 2020, 7, 191. [CrossRef]

73. Zhang, J.; Dong, L. Status and prospects: Personalized treatment and biomarker for airway remodeling in asthma. J. Thorac. Dis. 2020, 12, 6090-6101. [CrossRef] [PubMed]

74. Park, S.J.; Lee, K.S.; Lee, S.J.; Kim, S.R.; Park, S.Y.; Jeon, M.S.; Lee, H.B.; Lee, Y.C. L-2-Oxothiazolidine-4-carboxylic acid or $\alpha$-lipoic acid attenuates airway remodeling: Involvement of nuclear factor- $\mathrm{kB}(\mathrm{NF}-\mathrm{kB})$, nuclear factor erythroid 2p45-related factor-2 (Nrf2), and hypoxia-inducible factor (HIF). Int. J. Mol. Sci. 2012, 13, 7915-7937. [CrossRef] [PubMed]

75. Zuo, L.; Otenbaker, N.P.; Rose, B.A.; Salisbury, K.S. Molecular mechanisms of reactive oxygen species-related pulmonary inflammation and asthma. Mol. Immunol. 2013, 56, 57-63. [CrossRef] [PubMed] 